\title{
Place, community and information behavior: Spatially oriented information seeking zones and information source preferences
}

Amelia N. Gibson, Samantha Kaplan

\begin{abstract}
Even in a digitally advanced society, much of our daily lives is based in place, but information behavior research has largely ignored place as theoretically relevant to information behavior. This study explores the implications of a place-based approach to studying information practices, and examines factors that influence information seeking and sharing in place-based communities among parents of individuals with disabilities. Based on qualitative data gathered from 35 parents of individuals with disabilities, it proposes a spatial model of information source preferences based on the theory of information horizons, and discusses implications of the model for future research related to information seeking and places. It also presents substantive place-related findings about local information needs, including discussion of the local parent network as an information seeking system.
\end{abstract}

Published version can be found in Library \& Information Science Research:

Gibson, A., \& Kaplan, S. (2017). Place, community and information behavior: Spatially oriented information seeking zones and information source preferences. Library \& Information Science Research, 39(2), 131-139. doi:10.1016/j.lisr.2017.03.001 


\section{Introduction}

Developing more complex theoretical understandings of place is necessary if information science is to keep pace with and contribute to rapidly developing research, theory and practice in community, regional, environmental, and population health, urban and rural planning, and other sciences focused on improvement of life in spaces and places. Places are built in response to individual and collective problems, needs, and emotions (Tuan, 2001), much as information behavior occurs in response to human problems and needs. This research examines information access within local community contexts, and explores implications of a place-based approach to understanding information and service provision, information inequality, and inequity.

\section{Problem statement}

Library and information science (LIS) research has not developed a coherent, complex body of theory related to place, space, and information behavior. Instead, factors that differentiate individuals from one another (like place, race, and ethnicity) are often treated as theoretical (and sometimes methodological) noise-distractions from more favored, more easily operationalized concepts. When attention is paid to place and access, it is usually focused on information and communications technology (ICT) and broadband access, or internal library place-making as an expression of practitioner goals, rather than on understanding the interplay between place and information behavior in the broader community. This aversion to the complications inherent in the study of place limits the ability of the discipline to advance theoretical and practical discussions around the impacts of structurally reinforced (and spatially distributed) economic and social inequities on information seeking and access. It also limits the ability to dialog with disciplines that regularly use location and place as units of analyses. Finally, much of daily life is organized by place and in physical places. Ignoring place in information behavior research and focusing primarily on online information behavior ignores this reality and limits the impact that information behavior theory and research can have on a large portion of the population of the world.

This research explores intersections of place, information needs, and information access as experienced by 35 parents of individuals with Down syndrome in the United States. The findings are situated within the context of an exploratory grounded theory study on the influence of community and place on information needs, access, and behavior among parents of individuals with disabilities. Rather than focusing on specific information behaviors, the study focuses on using interac- tions among place, information needs, and information access (as indicated by resolution of information needs) to build a framework for describing and analyzing geographic zones of information access in local communities. That framework addresses

- Eliciting substantive descriptions of participant information needs, access to information sources, and where needs were resolved.

- Building a framework for describing community members' conceptualization of the infrastructure of information access (as related to location of information and services) in the local community; modeling participant expectations for resolution of 
information needs within the local community; and comparing expectations and actual needs resolution of different groups.

- Describing information needs of participants.

\section{Literature review}

Beginning in the 1990s and continuing into the first decade of the 21st century, social science research trended away from more place- based, geographical understandings of community toward sociological definitions centered on demographics and personal interest (Agnew, 1989; Gieryn, 2000). Even among geographers, the introduction of the Internet and high speed communication technology dethroned place, and place lost its primacy as an anchor for day to day life (Tuan, 2014). This shift was reflected in information behavior research, as theoretical work on communities leaned toward more sociological approaches to information behavior (Julien, Pecoskie, \& Reed, 2011; Veinot \& Williams, 2012; Wellman, 2001) and away from place related issues. More recently, a renewed understanding of the importance of places, communities, and the social impact of information (Bishop, 2011; Jaeger \& Burnett, 2010; Samek, 2007) has pushed LIS research toward explorations of community, access, and people in places.

Much of this work still ignores place in favor of more generally applicable context. Context as a concept is less specific than place, and here is defined as being of secondary importance to information behavior. Context describes the background conditions within which information behavior occurs (Dervin, 1997; Talja, Keso, \& Pietiläinen, 1999), but is not traditionally "defined as the phenomenon of interest" (Dervin, 1997, p. 14). While the study of context has gained importance (Greifeneder, 2014), its focus as secondary to information behavior and its use as a catch-all for descriptions of place, space, time, situation, organization, and social conditions (Johnson, 2003) limits its usefulness as a unit for analyzing information access (particularly in face-to-face communities). This research focuses specifically on place as the intersection of location, locale (i.e., infrastructure), and experience, and argues for stronger, more explicit, and more holistic conceptual and theoretical articulations of place in LIS research.

\subsection{What makes a place? Defining place and community}

This study builds on an interdisciplinary social science paradigm of place that incorporates definitions from human geography and sociology (Trentelman, 2009). The phenomenological perspective requires that places be interpreted through human experience, as the product of human interactions, and as the solution to human problems and needs (Tuan, 1975). To use Sonnenwald's (1999) phrasing, places and information are influenced by, and influence, human behavior. Within this perspective, places comprise location, or fixed coordinates on the globe; locale, that is, infrastructure, or "material setting for social relations" (Withers, 2009, p. 640); and sense of place, or experiential essence of a setting, interpreted and imbued with values and meanings (Agnew, 1989; Gieryn, 2000). Each of the component concepts of place are a combined manifestation of the spatial (including location), the structural (or the infrastructural), and the social (or the experiential). Massey (2005) ties place to time, describing this intersection as "throwntogetherness, the unavoidable challenge of negotiating the here and now...; and a negotiation which must take place within and between both human and nonhuman" (p. 140). 
Although they are similar concepts, place and community are not interchangeable. At its most basic, the term "community" describes any association of individuals with shared language, shared culture, or normative behaviors (Burnett, Besant, \& Chatman, 2001; Chatman, 1999; Day, 2006). Whether place-based or distributed, communities are usually developed to address some sort of collective need (Cavanagh, 2009) or to capitalize on shared identity. Place, on the other hand, describes the product of interaction between people and their physical environments. The term "place-based community" refers to a combination of community and physical space-a group of actors (individual, groups, or organizations) who to some degree share cultural experience-identity, social norms, language, and values (Jaeger \& Burnett, 2010), and geographic space (Day, 2006; Herb \& Kaplan, 1999).

In addition to conceptual similarities, places and communities tend to demonstrate structural parallels. Places have physical infrastructures comprised of buildings, streets and land features, whereas communities comprise social infrastructures, or information worlds, with actors who play specific social roles and have normative rules for behavior and values (Chatman, 1999; Jaeger \& Burnett, 2010), all of which contribute to "social differentiation, solidarity, and stability" (Veinot \& Williams, 2012, p. 848). Ideally, community members engage in collective self-determination with regards to information, knowledge, and values. According to this perspective, communities also have self-determined social and physical boundaries that are largely a product of internal norms and values. These borders are negotiated through shifting social relationships and group dynamics, and built organically through shared needs, behaviors, ideals, and values (Jaeger \& Burnett, 2010; Paasi, 1998, 2012), but can shift in response to outside pressures and social forces.

\subsection{LIS research: Explicit and implicit place}

A rich body of theory and research implicitly suggests that there is value in understanding place if the field is to understand information access and seeking behavior. In some cases, the idea of place is implicit in discussions on context. For example, information grounds theory (Fisher, Durrance, \& Hinton, 2004) examines temporally transient in- formation places. Others focus on time, space, and place as metaphors for information seeking. Dervin (1983) states that sense-making is built on the assumption "that all people live in time and space" (p. 7). Savolainen (2006) ties Dervin's time-space metaphor back to physical spaces and places by arguing that Dervin's spatial metaphors "have a basis in physical and cultural experience" (p. 1119). Others are more explicit about the role of place in shaping information behavior. Savolainen's (2009) analysis of information grounds and small worlds elucidates how spatial factors "constrain and afford information seeking and sharing" (p. 41) in small worlds, while they serve as "important qualifiers of information grounds" (p. 41). Studies examining the effects of rural environments on information behavior (Johnson \& Griffis, 2014; Kanungo, 2004) and library and facilities placement (Koontz, 2007) are all built on the assumption that place and location matter.

Community informatics literature defines communities as primarily and explicitly place-based (Le Roux, 2010). To resolve place-specific issues, Gurstein (2003) advocates for the creation of ICTs "with the full participation of the end users and the local community" (par. 53). Williams, Bishop, Bruce, and Irish (2012) identify two predominant meanings of 
community informatics, first as "the use of digital technol- ogies as a tool for community development" (p. 218), and second as a community support that "build[s] information resources and teach[es] skills to community members" (p. 218). This considerably broadens the realm of community informatics applications from problems to potential, aligning with Gurstein's (2003) emphasis on the ability of ICTs "to enable and empower community processes" (p. 11). The present research argues for a similarly agentic view of place-related information behavior theory (Trentelman, 2009) as a byproduct of socially determined needs, as influencing behavior, and as regulating change.

\subsection{Places, communities, and health}

As will be seen below, a large portion of the everyday life information that was sought by participants in the present study was related in some way to health. Health status reflects place (Marmot, Friel, Bell, Houweling, \& Taylor, 2008; McLaughlin, Thompson, Parahoo, Armstrong, \& Hume, 2007), and variations in systemic approaches to face-to-face health information provision and health education can result in health disparities. Marmot et al. (2008) call for rectification of health inequity by remedying "the inequitable distribution of power, money, and resources" (p. 1661) such as access to health education-much of which varies by school district or school zone.

The importance of community infrastructure is particularly pronounced when examining accessibility for individuals with disabilities. McDonald, Williamson, Weiss, Adya, and Blanck's (2015) assessment of community resource accessibility for individuals with disabilities found, across the 12 communities (from six states) studied, "accommodations, adaptive equipment, and assistive technology that enable access were available less than $50 \%$ of the time" (p. 355). Often when resources and services were physically accessible, related information was not. These types of inequities are also perceptible beyond medical services and information sources. They extend into schools, therapy, government agencies, and other local organizations, and influence individual and family experiences of local communities (Gibson, 2014).

These inequities sometimes push individuals with disabilities to find the information they need in other places. Studies of online communities devoted to health information have gleaned that these communities serve two primary functions: provision of health information and provision of social support (Johnston, Worrell, Di Gangi, \& Wasko, 2013; Nambisan, 2011; Plantin \& Daneback, 2009). Johnston et al. (2013) find that, for individuals with personal computer and Internet access, and sufficient information literacy, participating in online health communities can promote "positive patient empowerment" (p. 223). Unfortunately, Internet access and personal computer ownership are not uniformly distributed. Uneven distribution of Internet access in the United States (National Telecommunications and Information Administration, 2013) and in other geopolitical regions (Organization for Economic Co-operation and Development, 2012; Organization for Economic Co-operation and Development, 2016) is well documented, and has implications for parents' ability to access online support networks and information. Some of the same systemic inequities that prevent people with disabilities from accessing information in their local communities (e.g., underfunded communities or school systems, or rural areas with limited access to medical care) make information access via the Internet difficult. Even on the Internet, place matters. 


\subsection{Information horizons}

The present research reflects Sonnenwald's (1999) information horizons theory, and builds on Savolainen's (2007) further development of the spatial metaphor of the information horizon. Instead of focusing on information source zones that progress from most to least important resources, this study characterizes information seeking zones and horizons as spatially oriented. It focuses on the resolution of information and service needs in terms of distance, space, and place.

Table 1 Sensitizing theory: Meta-categories.

\begin{tabular}{|c|c|}
\hline Category & Analytical questions and examples \\
\hline $\begin{array}{l}\text { Actors/social } \\
\text { roles }\end{array}$ & $\begin{array}{l}\text { Who or what are the stakeholders, participants, or resources named? What } \\
\text { role does this person occupy? }\end{array}$ \\
\hline $\begin{array}{l}\text { Information } \\
\text { behaviors }\end{array}$ & How do actors seek, avoid, exchange, or use information? Mechanisms. \\
\hline Social norms & $\begin{array}{l}\text { What cultural expectations exist? Shared language, cultural norms and } \\
\text { expectations, etc., shared by actors. Indicate membership in community. }\end{array}$ \\
\hline $\begin{array}{l}\text { Information } \\
\text { values }\end{array}$ & Is there a hierarchy of preferred information types? How is value measured? \\
\hline $\begin{array}{l}\text { Boundary } \\
\text { objects }\end{array}$ & $\begin{array}{l}\text { Where are the edges of the information world? Objects, meanings, spaces, } \\
\text { places that are shared by individuals from more than one world. Shared but } \\
\text { contested meanings. }\end{array}$ \\
\hline
\end{tabular}

\section{Methodology}

This grounded theory study takes a multi-method approach toward data collection and analysis. Between June 2011, and December 2014, 35 parents and legal guardians of people with Down syndrome participated in 45-90 min semi-structured interviews, geospatial mapping of local information sources and services, and egocentric social network mapping of people and organizations they considered to be a part of their local community of support.

Down syndrome is one of the most commonly diagnosed genetic conditions at birth in the United States (Presson et al., 2013). This meant that study participants could be found across a range of racial, ethnic, and geographic groups. Because of increasing lifespans, and acceptance of the contributions people with Down syndrome can make to their communities, parents of individuals with Down syndrome now find themselves experiencing an expanding learning curve about living with Down syndrome in local communities (rather than in isolated medical or psychiatric facilities). The constantly changing nature of community based health and everyday life information for this group provides rich opportunities for examining information seeking and sharing in relation to place.

\subsection{Sensitizing theory: Grounded theory methodology and information worlds}


This qualitative, constructivist grounded theory study (Charmaz, 2014) examines place and information behavior from the participant perspective, as interpreted by the researcher. This approach assumes that all research represents, to some degree, multiple perspectives, that all research is co-constructed among participants and researchers, and that certain bodies of theory inform the researcher's perspective. While these theories and their associated concepts and propositions are not accepted wholesale, they are acknowledged as influencing the researcher's approach to the data and the theory building process. From this symbolic interactionist perspective, data are the result of a negotiation among numerous factors, including (but not limited to) the researcher's choice of questions, identity, participant memory, and intention (Jeon, 2004). It is the researcher's responsibility to faithfully represent and analyze participants' freely expressed experiences unencumbered by explicitly imposed explanatory concepts, while recognizing the limitations inherent in self-reported, spoken data that is reliant on participant memory.

The theory of information worlds (Burnett, 2015; Jaeger \& Burnett, 2010) provides a guiding framework for data collection and an organizing framework for data analysis. It explicitly addresses the social infrastructure of communities, and directs the researcher to examine social norms, actors and social types, information behaviors, information values, and boundaries in the description and analysis of an information world. In this study, the theory provided guidance for designing interview prompts (which are intended to further or deepen discussion during interviews) by providing structure for additional thematic exploration, and an initial framework for identification of phenomena and concepts during data analysis (see Table 1 for concepts and corresponding analytical questions). Because this theory is not predictive or prescriptive at the level of specific populations, it does not violate Corbin and Strauss (2015) or Charmaz's (2014) suggestion that initial grounded theory should not test the validity of currently existing theoretical frameworks.

\subsection{Study sample and recruiting}

Sampling and data collection was done in two rounds. Initial recruiting was done through advertising on local parent support group listservs and Facebook groups. Snowball sampling was used to expand the group beyond highly-involved parent support group members, and the resulting study sample included 28 parents of individuals with Down syndrome between six months and 33 years old in two counties in the southeastern United States. After initial analysis of this data was complete, the parameters for the study sample were expanded and recruiting was done to encourage a more racially heterogeneous sample, and to respond to theoretical questions about whether findings were related specifically to the first two study communities. The final expanded sample included 35 parents from 5 states (Texas, California, North Carolina, Florida and Georgia). Of the respondents, 6 were black or African-American and 29 were White (including 5 who identified as Hispanic or Latino and White). Participants ranged in age from 26 to 73 years old (M 44), and children's ages ranged from 3 months to 38 years old (M11).

\subsection{Data collection instruments: Interviews and mapping}

Respondents participated in semi-structured interviews and created maps of their local support communities. Interviews were based on the information horizons protocol designed by Sonnenwald, Wildemuth, and Harmon (2001), and were designed to gather a wide range 
of information about participants' experiences seeking information on behalf of their children. Participants were asked specifically about information-seeking related to government services, medical care, and education over the previous year. They were also asked to describe any instances during their child's, or children's, lifetime in which they could not find sufficient information, times when they experienced information overload, and at least one time in which they were satisfied with information received. Participants were also asked to evaluate their local communities of support and to share advice that they would give to the parents of a newborn with Down syndrome.

Finally, participants were asked to build egocentric social network maps of their support communities, with themselves and immediate families in the center, and members of the support community as nodes, adding names and addresses of places within the local community where they found information or services.

\subsection{Interview analysis}

Grounded theory methodology involves a combination of inductive and abductive strategies, resulting in an iterative process of data collection and analysis (Charmaz, 2014). Each round of findings informed subsequent data collection activities. Initial open coding identified emergent phenomena and categories. Consequent rounds of coding used information worlds theory as sensitizing theory, but researchers continued to allow emergent codes and categories to drive the coding process. Initial coding was based on a series of questions (see Tables 1 and 2), and later coding identified motivations and contexts for phenomena. Data were analyzed until theoretical saturation was reached, or until the identified concepts were fully developed (see Tables 3 and 4 for coding examples). This concept of theoretical saturation is a key feature of grounded theory research (Charmaz, 2014; Corbin \& Strauss, 2015).

Table 2 Open coding criteria

\begin{tabular}{ll}
\hline Coding category & Associated questions \\
\hline Identification of concept & $\begin{array}{l}\text { What is going on in the data? Identify, summarize, name } \\
\text { phenomenon or concept. }\end{array}$ \\
Context for phenomena & $\begin{array}{l}\text { Where is this happening? When did it happen? Did } \\
\text { something else happen before or after? } \\
\text { Why did this happen? Did something else happen before }\end{array}$ \\
Motivations of participants & $\begin{array}{l}\text { or after? What was the stated reason? Does the } \\
\text { researcher see an unstated motivation? }\end{array}$ \\
Process (development of & $\begin{array}{l}\text { How did this happen? Did this happen at one specific } \\
\text { thoughts or behaviors) }\end{array}$ \\
time, or over a period of time? \\
Effect of phenomenon & What influence does this phenomenon have on other \\
\hline
\end{tabular}

Table 3 Coding example for zone 1 (home).

\begin{tabular}{lll}
\hline Selected passages & Open codes & Categories \\
\hline
\end{tabular}




\begin{tabular}{|c|c|c|}
\hline $\begin{array}{l}\text { But we did have an early intervention } \\
\text { specialist that came in through the ARC, } \\
\text { she came to the house and helped me } \\
\text { with those sorts of things. }\end{array}$ & $\begin{array}{l}\text { Early } \\
\text { intervention } \\
\text { Parent } \\
\text { training/ } \\
\text { childrearing }\end{array}$ & $\begin{array}{l}\text { Purpose/ } \\
\text { information } \\
\text { need }\end{array}$ \\
\hline $\begin{array}{l}\text { The hospital set me up with a social } \\
\text { worker who then set me up with Early } \\
\text { Intervention - someone came to our } \\
\text { home. }\end{array}$ & $\begin{array}{l}\text { Social worker } \\
\text { Therapy } \\
\text { Home } \\
\text { Hospital }\end{array}$ & Location \\
\hline \multicolumn{3}{|l|}{$\begin{array}{l}\text { Case worker had already been out to } \\
\text { my house and matter of fact I still see } \\
\text { her around town }\end{array}$} \\
\hline $\begin{array}{l}\text { Definitely early Ilintervention services } \\
\text { through Children's Home Society. They } \\
\text { came to us, so that was extremely } \\
\text { helpful. }\end{array}$ & & \\
\hline
\end{tabular}

\subsection{Trust and trustworthiness}

As the mother of a child with Down syndrome, the primary researcher shared commonalities that helped in building rapport with participants, and gave insight into question selection, phrasing, and data analysis. Understanding of some shared social norms, language preferences, and parent concerns helped in building trust with individual participants and the disability community and parent support group. The secondary researcher offered an alternative perspective through open and axial coding during later stages of data analysis. Researchers debriefed weekly to discuss coding categories and to ensure intercoder agreement as theory was developed. Researchers used extensive memoing, constant comparison, and member checking to ensure rigorous investigation of concepts and increase trustworthiness during theory development.

\section{Findings}

The following interrelated themes associated with place and information access were identified:

(1) A concept of information access based on level of effort, measured here in distance traveled and time spent seeking information or services. This resulted in development of a taxonomy of spatially- oriented information seeking zones defined by participants.

(2) Information needs identified by participants. Because specific needs differed according to child age and other factors, needs were grouped into categories.

(3) Connections between identity, intersectionality, and information access. 
These themes are described below. Information seeking zones and their associated needs (themes 1 and 2) are described in Section 5.1. Connections among identity, place, and information access are discussed in Section 5.2.

Table 4 Coding example for zone 3 (regional travel).

\begin{tabular}{|c|c|c|}
\hline Selected passages & Open codes & Category \\
\hline $\begin{array}{l}\text { Because sometimes they're all the way } \\
\text { out on the other side of _, and it's like } \\
\text { a } 45 \text { min drive and you're like, okay I } \\
\text { can't do this }\end{array}$ & $\begin{array}{l}\text { Parent } \\
\text { support Meet } \\
\text { other } \\
\text { parents/social } \\
\text { support }\end{array}$ & $\begin{array}{l}\text { Purpose/ } \\
\text { information } \\
\text { need }\end{array}$ \\
\hline $\begin{array}{l}\text { It was through the __ Down syndrome } \\
\text { organization but that's a hike for me. } \\
\text { You know, because like it takes almost } \\
\text { a half an hour to get to the therapeutic } \\
\text { center }\end{array}$ & $\begin{array}{l}\text { Medical } \\
\text { information/ca } \\
\text { re Mom's } \\
\text { night out } \\
\text { Doctors } \\
\text { (specialists) }\end{array}$ & $\begin{array}{l}\text { Location/ } \\
\text { distance }\end{array}$ \\
\hline $\begin{array}{l}\text { Her ENT - she sees him every four } \\
\text { months, same thing, we travel to __, to } \\
\text { see him. }\end{array}$ & $\begin{array}{l}\text { ENT } \\
\text { CONFERENC } \\
\text { E Down at } \\
\text { in Miami [45 } \\
\text { min away] }\end{array}$ & \\
\hline $\begin{array}{l}\text { I did attend a conference last year at } \\
\text { university, and there is a good } \\
\text { movement to bring on, it starting with } \\
\text { students with learning disabilities. }\end{array}$ & $\begin{array}{l}\text { North end of } \\
\text { county } \\
\text { [approx. } 60 \\
\text { min] that's a } \\
\text { hike for me }\end{array}$ & \\
\hline \multicolumn{3}{|l|}{$\begin{array}{l}\text { I had to take him to three different ENTs } \\
\text { because he was getting chronic ear } \\
\text { infections and colds and I ended up } \\
\text { taking him to three MPAs and an } \\
\text { allergist and then the allergist } \\
\text { suggested I take him to the chief of } \\
\text { otolaryngology at the University of __. }\end{array}$} \\
\hline \multicolumn{3}{|l|}{$\begin{array}{l}\text { That was one of the main reasons I } \\
\text { moved out of that county, was because } \\
\text { that county doesn't provide as much, } \\
\text { the special Olympics was always in } \\
\text { or you had to drive an hour away, all } \\
\text { these other things. }\end{array}$} \\
\hline $\begin{array}{l}\text { But we lived in south end _ county and } \\
\text { she had to ride in a van would come } \\
\text { home dripping sweat because it's on }\end{array}$ & & \\
\hline
\end{tabular}


north end of county.

\subsection{Information seeking zones and information needs}

Participant descriptions of information and service-seeking emphasized the importance of information and service access for parents' development of a positive sense of place. Many participants evaluated their communities based on proximity to information, services, social programs, and expertise. Because many parent information needs were fulfilled in face-toface settings such as healthcare settings, therapists' offices, and schools, participants often described their communities by listing nearby (or easily accessible) organizations that provided services or information as service (see Section 5.1.2 for more on information as service).

This proximity was often described in terms of travel time or distance from the home, hospital, or other place of residence, and served as a proxy for describing levels of community access to information and services related to Down syndrome. In their evaluations, most participants indicated their satisfaction or dissatisfaction with their proximity to information and services.

Fig. 1 illustrates one simple example of a spatial information access model based on participant descriptions. The model flattens the physical landscape of the local place-based community to five zones (Sections 5.1.1 through 5.1.5 describe each zone). In this version of the model, movement over space is measured in travel minutes. The size, number and unit of measurement for travel zones all reflect themes and general trends found in interview, map, and social network data. This model (as compared to maps of physical space) captures data about community members' conceptualization of the boundaries and structure of local place-based communities, provides a framework for capturing data about expectations and preferences for location of information and services in local communities, reduces the complexity associated with mapping distance from multiple residences, and reduces risk of deductive disclosure associated with mapping participant addresses and information sources in the local community.

Fig. 2 compares expectations of information access and information need fulfillment related to early intervention for the eight participants ( 3 rural and 5 urban) who discussed early intervention information needs and expectations. This framework for comparison provides a model for quantifying and visualizing differences in expectations for information access and actual achievement of that access.

In this example, parents shared similar expectations about the location of early intervention and therapy services for young children, but only $33 \%$ of rural parents' expectations were met (as compared to $100 \%$ of urban parents). The remaining parents had to travel outside of zone 1 to zone 2 for information and services. In this example, each participant described a single zone expectation, so the number of expectations and information needs met equaled the total of participants who discussed the information need.

\subsubsection{Zone 0: The self}


Zone 0 represents the self, or the individual as she or he physically moves through the information world (represented by the spatial zone model) in search of information. Use of mobile web search or the Internet at home (or at work) does not represent additional effort or travel time to resolve an information need (or it did not for parents in this sample). As such, Internet searches are represented as occurring in zone 0 . In the case of an individual who used a local library in the absence of Internet at home, Internet searches might occur in another zone (indicating required travel).

Parents discussed the Internet as a point of access for three types of information: basic factual information (about a range of topics, including education or medical information about Down syndrome), tacit information about life and well-being, and localized or processoriented information (e.g., how to apply for entry to a local school, or how to find a local doctor that specialized in children with Down syndrome). They described both interactive and transactional (interacting via social media or online applications) and more passive (reading or skimming static websites) modes of information seeking. Interaction with the local community through the internet presented the possibility of anonymity in information seeking, as parents used social media and email listservs to request information from other parents through the local parent support group.

She'll ask if somebody needs help with certain service - a child has this problem - then you'll get the email, you're part of the email blast, and then they'll say, "any parent have that problem with their child?" So we share stories with each other and that really helps the parents in that sense (Part $22 \mathrm{~T}$ ).

Because the bulk of daily communication with other parents occurred via the Internet, limited Internet access, limited knowledge of social media, and limited English all presented barriers to participation in the local parent support group.

They don't even speak English, they don't even have an email you know because that's what I was...to ask them if I can get an email from them so they be on the listserv, but no, they don't even have an email. (PartD1).

These non-English speaking families did reach out to other Spanish-speaking families outside of the local community for emotional support, but this left a gap in their knowledge about local services and information, because they could not rely on the local parent network for referrals and information about local services. 


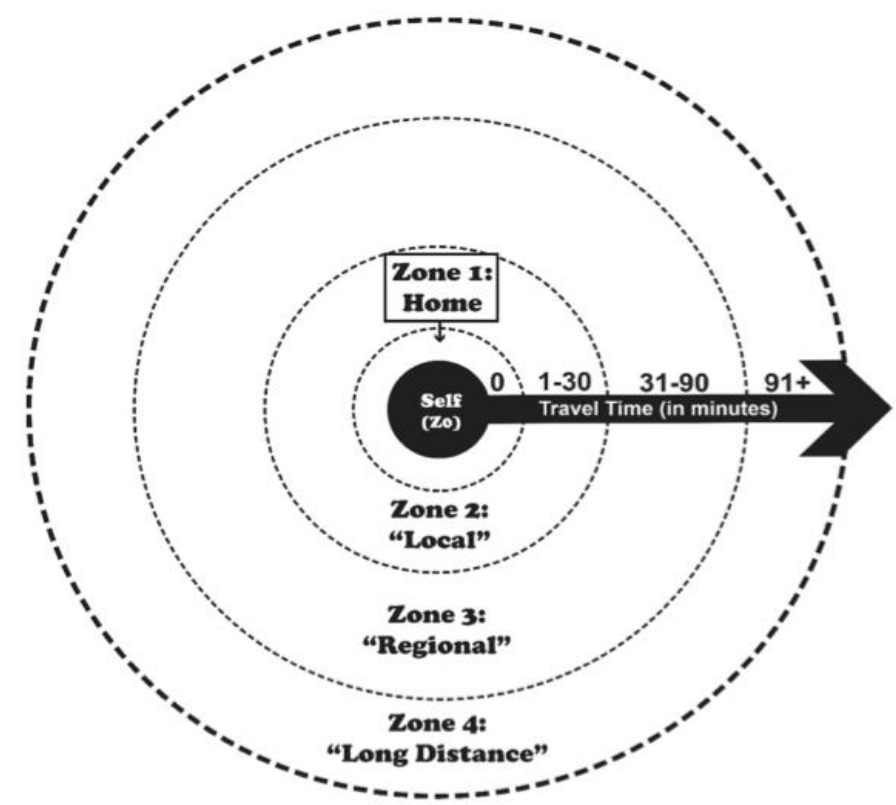

Fig. 1. Spatial information seeking zone model.

\subsubsection{Zone 1: The home}

Zone 1 encompassed the home and temporary home spaces, such as the hospital or neonatal intensive care unit (NICU). Information needs met within these spaces were most frequently associated with young children. Parents expected that information needs related to childcare, therapy, early intervention, and finding and hiring therapists who had specific knowledge about Down syndrome would be resolved in zone 1. Therapy information as service, or information or instruction given to parents so that they could manage some portion of their child's care also happened in zones 1 (for children ages $0-3$ ) and zone 2 (for older children and adults). For example, many parents of young children received weekly instruction on daily therapy techniques to use until the next weekly session (which would include an assessment and further instructions). This information as service was also an important feature of doctors' visits (where parents sometimes received a similar combination of assessments and instructions) and other services as children aged. For parents who lived in rural areas, finding early childhood therapists who would be willing to travel out to their homes was sometimes a challenge. This was reflected as a higher number of parents of young children having therapy information needs met in zones 2 and 3 , as compared to peers in more urban areas. 


\section{Early Intervention}

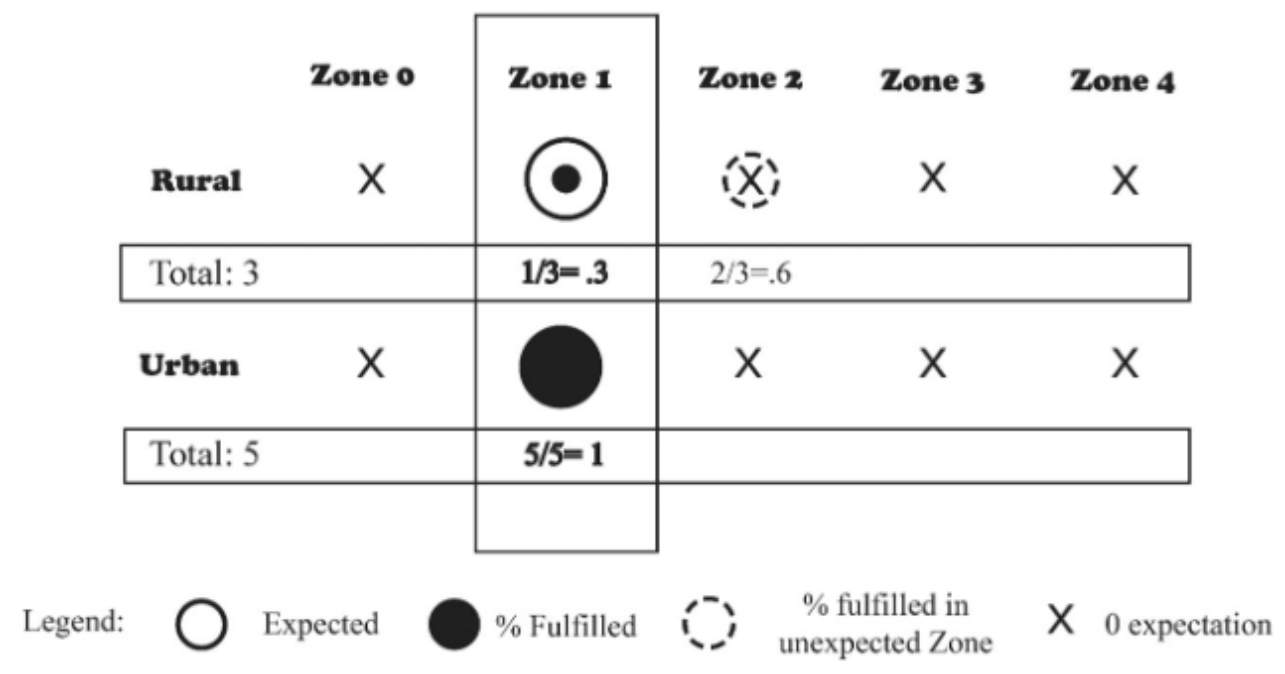

Fig. 2. Comparison of access preferences and fulfillment for early intervention among rural vs. urban parents.

\subsubsection{Zone 2: Close to home, municipal, "local"}

Zone 2 comprised that space within 30 min of travel time from the participants' homes. Here, information needs related to education (most frequently during meetings at local schools or administrative buildings) and employment (through visits to worksites or training programs) were fulfilled. Regularly scheduled social and recreational activities often occurred within this zone. Zone 2 was primarily accessed through personal vehicles or public transportation (either municipal or school bus systems).

\subsubsection{Zone 3: Regional}

Zone 3 comprised the space between 30 and 90 min of travel from the participant's home (see Table 3 for coding examples from zone 3). This zone encompassed the majority of medical care and special, less frequently-occurring parent support group programming. It also included social events with other parents. There was some discrepancy as to what constituted "local" and what constituted "regional," with some parents differentiating between Zone 2 as their own personal local communities and Zone 3 as a shared, larger version of the local community that was more expansive geographically. These parents often described Zone 3 as encompassing entire counties and otherwise informally established regions (e.g., "the research triangle" or "the Dallas-Fort Worth area"), whereas Zone 2 described their neighborhoods and immediately surrounding areas.

\subsubsection{Zone 4: Long distance}

Zone 4 included travel over 90 min, and generally encompassed the contiguous United States. In most cases, zone 4 was reserved for highly- skilled specialist care, surgery, and national conferences. International travel was not discussed by any of the study participants.

\subsection{Community, identity, and intersectionality}


Race and ethnicity influenced participant expectations for information access, and, for some, increased travel time to find suitable information sources and services. Issues related to race and ethnicity were mentioned explicitly in 6 out of 35 interviews. Fig. 3 illustrates differences in expectations and preferences and disparities in fulfillment among white non-Hispanic, Hispanic or Latino, and Black non-Hispanic parents for specialist medical information, such as cardiology, ophthal- mology, and endocrinology. It shows that, despite mostly similar expectations, rates of fulfillment differed. All 3 parents who expected to find information about medical (specialist) information in zone 2 were able to find it in that zone, whereas 1 out of 2 Hispanic or Latino parents and 2 out of 3 black parents were able to find it in zone 2 . Four white parents who expected to find this information in zone 3 described finding it regularly in zone 2 .

In this example, some parents expressed multiple expectations or preferences. For the sake of simplicity, zone 0 is not included in this representation, and the stated zone closest to 0 is represented. This more granular examination of access requires representation of both "fulfilled as expected," and "fulfilled in a different zone" in order to avoid oversimplifying data. For example, $50 \%$ of Hispanic or Latino participants who expected to find medical specialist information in zone 2 (within 30 min of home) found it there. One found it in zone 3 (31-90 min from home). If that 1 were combined into a single metric with the 2 (out of 3 ) in zone 3 who had their expectation fulfilled, it would appear as if 3 out of 3 had been fulfilled, and zone 3 would have a score of 1 , or $100 \%$. At least two scores per zone are needed to avoid this type of misrepresentation and accurately represent the differences between fulfilled expectations and needs fulfilled outside of expected zones. Intersectionality (Crenshaw, 1991), as a concept, underscores the fact that the ways in which these inequities are experienced - their scope, depth, and manifestations - are not uniform across the local community. The proposed model helps quantify and illustrate social isolation and local structures of privilege that disenfranchise specific groups, and the disability community as a whole.

\section{Discussion}

Places and community are the product of human needs, and the summary of human experiences and behavior. A spatial model of information access zones provides a framework for making differences in information access in place-based communities more explicit. Understanding where people expect to find information, and when those expectations are (or are not) met can help identify information deserts or gaps in information access that are not related to ICTs or broadband access. In doing so, it can help inform quantitative and qualitative examination of information needs within place-based communities and explicit examination of local expectations regarding space, time, and effort needed to access information. Those expectations need not be expressed using the same units of analysis as those represented in this study. Participants in this study sample overwhelmingly described information seeking effort in terms of face-to-face locations and travel time. Others might describe it in terms of minutes spent on the phone trying to find information or access a service.

\subsection{Multiplicity and inter-group comparisons}


Richer theoretical and empirical models of place and information access prompt deeper thinking about the impacts of identity, geography, income, and other factors on information access (and by extension, information poverty). Different people experience places differently. Hence, different people can inhabit the same physical space, but occupy separate (and often unequal) information places. Massey's (2005) description of place as "internally multiple," (p. 182) and simultaneously representative of multiple scales and realities reflects this concept. Similarly, Sonnenwald's (1999) information horizons theory, Jaeger and Burnett's (2010) information worlds, Chatman's (1999) small worlds, and Fisher et al.'s (2004) information grounds acknowledge the social multiplicity inherent in physical information places. In their explication of social, physical, and temporal infrastructures of information worlds, these approaches implicitly address scale and place in a way that supports examination of multiple, co-occurring, co- located social information networks. A more explicit focus on communities and places would build on these approaches by examining the physical, organizational, financial, and social infrastructures of local communities beyond ICT infrastructure. Regional politics, local demographics, and associated socio-cultural norms all influence individual definitions of information needs, zone size, and expectations for need fulfillment.

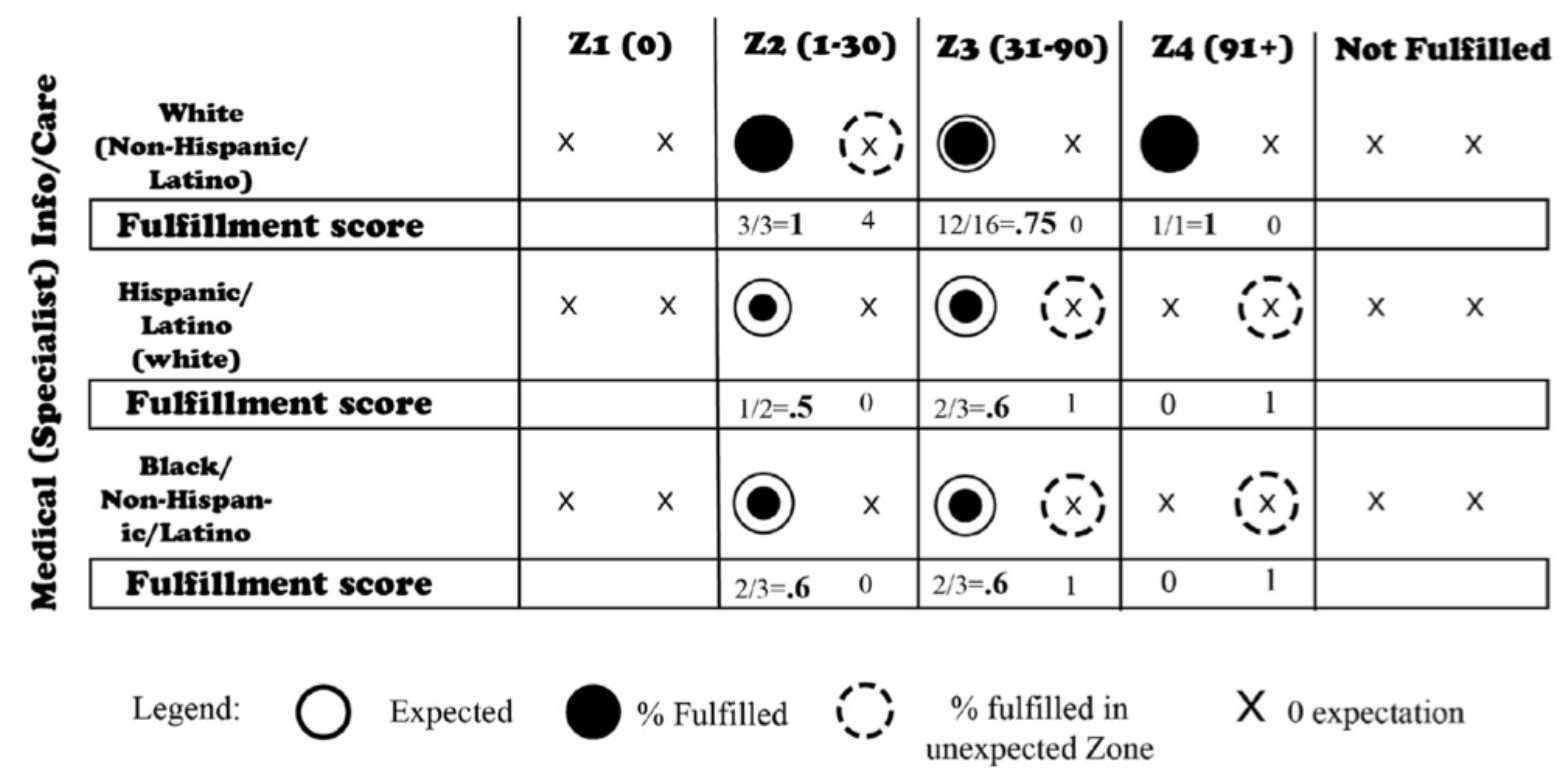

Fig. 3. Comparison of access preferences and fulfillment for medical specialist information among White, Hispanic, and Black parents.

6.2. Equity, equality, and expectations

Comparing access models illustrates differences in expectations for information access, differences in the scale of physical space within which participants seek information, and inequities in information access among participants. In their spatial access framework, Lievrouw and Farb (2003) contrast equity with equality, equity being defined as "the fair or reasonable distribution of information among individuals, groups, regions, categories, or other social units, such that those people have the opportunity to achieve whatever is important or meaningful to them in their lives" (p. 503). Inequity in information access has implications for health, education, income, and political participation. This focus has implications for planning information and services for place-based communities. Rather than focusing on giving each indivi- dual access to the same amounts of information, or 
information in the same spaces, an equity approach focuses on understanding what information individuals need to meet personal goals, what level of effort they are capable of exerting to seek information, and what is needed to meet those access needs.

Racial difference provides an example of how multiplicity and inequity manifest among different groups occupying the same local community. Crenshaw (1991) describes intersectionality as the effect of "overlapping systems of subordination" (p. 1265) in social worlds (e.g., combinations of race and disability, or dual diagnosis). Reduced participation and representation in local parent support groups indicated an intersection of race and disability that had negative implications for participants who were also people of color. As people of color, many of their needs were not met in the overwhelmingly white local parent support group, and as members of the disability community, many of their needs were not met in larger communities of people of color. Some coped by seeking information outside of the local community or outside of the disability community, shifting their information seeking to higher numbered zones, as compared to white participants. Similar patterns were found among parents of individuals with dual diagnoses. Developing ways to conceptualize, describe, quantify, and compare these types of place-centered multiplicities could highlight functional inequity in information access, and help facilitate greater equity in information and service planning, dissemination, and im- plementation. Explicit definition of information seeker expectations, understanding of information access zones, and description of information needs provide an alternative to organization-centered information and service provision models.

\subsection{Limitations}

As interpretive, qualitative research, this study does not make generalizable claims about the information behaviors of parents of children with Down syndrome. Instead, it focuses on implications of these findings for development of conceptual models for describing information access in place-based communities. Further research is needed to explore the substantive findings of this study, and to explore geographic variations in parents' experiences. Additionally, because of the age of the participants' children, issues related to late life, such as Alzheimer's and dementia (Kozma, 2008), were not addressed in this study. The geographic and chronological spread of the data represent possible limitations and strengths of the study. Limited data collection in secondary communities resulted in the incorporation of limited participant perspectives, but within the given theoretical sampling framework, additional data was collected to test specific theoretical questions (for thematic development) rather than to confirm the similarity of substantive participant experiences. $A$ similar rationale was used for the chronological spread. The researchers were interested in whether there were any indicators of collective changes in specific substantive information seeking experiences, or more basic conceptual or behavioral approaches to information seeking over the course of the study period. There were not.

\section{Conclusion}

Although this research focuses on place as it relates to the information behaviors of parents of individuals with special needs in particular, the importance of place is not limited to these groups, or the units of analysis examined here. Fundamentally, the framework describes four facets of information access in local communities: 
1. Spatial information access zones in terms of distance from the information seeker;

2. Information seeking effort (in this case measured by minutes of travel);

3. Preferences or expectations for fulfillment of information needs in certain zones;

4. Measuring fulfillment of those preferences or expectations.

Developing more place-based and spatially oriented understandings of information access support more structured examination of information inequity. Further development of concepts related to place and information behavior supports more rigorous examination and improvement of information access and services in local communities. It also expands the capacity of the discipline to develop a more practically grounded body of social information behavior theory, and to contribute to interdisciplinary research in place-based communities (e.g., in community health, social environmental health, or smart communities planning). Finally, it gives researchers additional language with which to discuss variations in information seeking experiences, and, most importantly, the ability to improve information access for more diverse groups of people.

\section{Acknowledgements}

This research was partially funded by the School of Information and Library Science at the University of North Carolina at Chapel Hill. We thank our colleague David Gotz, who provided insight related to visualization of the model.

\section{References}

Agnew, J. 1989. Introduction. In The power of place: Bringing together geographical and sociological imaginations, edited by J. Agnew, \& J. S. Duncan, 21-36. London, England: Routledge.

Bishop, Bradley Wade. 2011. Location-based questions and local knowledge. Journal of the American Society for Information Science and Technology 62 (8): 1594-603.

Burnett, Gary. 2015. Information worlds and interpretive practices: Toward an integration of domains. Journal of Information Science Theory and Practice 3 (3): 6-16.

Burnett, Gary, Michele Besant, and Elfreda A. Chatman. 2001. Small worlds: Normative behavior in virtual communities and feminist bookselling. Journal of the American Society for Information Science and Technology 52 (7): 536-47.

Cavanagh, Allison. 2009. From culture to connection: Internet community studies. Sociology Compass 3 (1): 1-15.

Charmaz, Kathy. 2014. Constructing Grounded Theory. London: SAGE.

Chatman, Elfreda A. 1999. A theory of life in the round. Journal of the American Society for Information Science 50 (2-3): 207-17.

Corbin, Juliet M, and Anselm L Strauss. 2015. Basics of Qualitative Research: Techniques and Procedures for Developing Grounded Theory. Los Angeles: SAGE.

Crenshaw, K. 1991. Mapping the margins: Intersectionality, identity politics, and violence against women of color. Stanford Law Review, 43(6), 1241-1299.

http://dx.doi.org/10.2307/1229039. 
Day, G. 2006. Community and everday life. New York, NY: Routledge.

Dervin, B. 1983. An overview of sense-making research: Concepts, methods and results. Retrieved from

http://faculty.washington.edu/wpratt/MEBI598/Methods/An\%20Overview\%20of\%20Sens e-Making\%20Research\%201983a.htm.

Dervin, B. 1997. "Given a context by any other name: Methodological tools for taming the unruly beast." edited In Information seeking in context, edited by P. Vakkari, R. Savolainen, \& B. Dervin 13-38. London, England: Taylor Graham.

Fisher Karen E., Durrance Joan C., and Hinton Marian Bouch. 2004. "Information Grounds and the Use of Need-based Services by Immigrants in Queens, New York: A Contextbased, Outcome Evaluation Approach." Journal of the American Society for Information Science and Technology 55 (8): 754-66. https://doi.org/10.1002/asi.20019.

Gibson, Amelia N. 2014. A better place? factors in community assessment for parents of children with down syndrome. Proceedings of the American Society for Information Science and Technology 51 (1): 1-10.

Gieryn, Thomas F. 2000. A space for place in sociology. Annual Review of Sociology 26 (1): 463-96.

Greifeneder, E. 2014. Trends in information behaviour research. Information Research-an International Electronic Journal 19 (4).

Gurstein, Michael. 2003. Effective use: A community informatics strategy beyond the digital divide. First Monday 8 (12).

Herb, Guntram Henrik, and David H Kaplan. 1999. Nested Identities: Nationalism, Territory, and Scale. Lanham, Md.: Rowman \& Littlefield Publishers.

Jaeger, Paul T, and Gary Burnett. 2010. Information Worlds: Social Context, Technology, and Information Behavior in the Age of the Internet. New York: Routledge.

Jeon, Yun-Hee. 2004. The application of grounded theory and symbolic interactionism. Scandinavian Journal of Caring Sciences 18 (3): 249-56.

Johnson, Catherine A., and Matthew R. Griffis. 2014. The effect of public library use on the social capital of rural communities. Journal of Librarianship and Information Science 46 (3): 179-90.

Johnson, J. David. 2003. On contexts of information seeking. Information Processing and Management 39 (5): 735-60.

Johnston, Allen C., James L. Worrell, Paul M. Di Gangi, and Molly Wasko. 2013. Online health communities: An assessment of the influence of participation on patient empowerment outcomes. Information Technology and People 26 (2): 213-35.

Julien, Heidi, Jen (J L.). Pecoskie, and Kathleen Reed. 2011. Trends in information behavior research, 1999-2008: A content analysis. Library and Information Science Research 33 (1): 19-24. 
Kanungo, Shivraj. 2004. On the emancipatory role of rural information systems. Information Technology \& People 17 (4): 407-22.

Koontz, Christie M. 2007. A history of location of U.S. public libraries within community place and space: Evolving implications for the library's mission of equitable service. Public Library Quarterly 26 (1-2): 75-100.

Kozma, Chahira. 2008. Down syndrome and dementia. Topics in Geriatric Rehabilitation 24 (1): 41-53.

Le Roux, C. J. B. 2010. Social informatics vs community informatics: A brief overview of their origins and current status. Mousaion 28 (1): 34-44.

Lievrouw, Leah A., and Sharon E. Farb. 2003. Information and equity. Annual Review of Information Science and Technology 37 (1): 499-540.

Marmot, Michael, Prof, Sharon Friel PhD, Ruth Bell PhD, Tanja AJ Houweling PhD, Sebastian Taylor PhD, Commission Social Determinants Hlt, and Commission on Social Determinants of Health. 2008. Closing the gap in a generation: Health equity through action on the social determinants of health. Lancet, the 372 (9650): 1661-9.

Massey, Doreen B. 2005. For Space. London; Thousand Oaks, Calif.: SAGE.

McDonald, Katherine E., Pamela Williamson, Sally Weiss, Meera Adya, Peter Blanck, and DBTAC Southeast ADA Ctr PAR Res. 2015. the march goes on: Community access for people with disabilities. Journal of Community Psychology 43 (3): 348-63.

Mclaughlin, Marian, Kate Thompson, Kader Parahoo, Janice Armstrong, and Allison Hume. 2007. Inequalities in the provision of sexual health information for young people. Journal of Family Planning and Reproductive Health Care 33 (2): 99-105.

Nambisan, Priya. 2011. Information seeking and social support in online health communities: Impact on patients' perceived empathy. Journal of the American Medical Informatics Association 18 (3): 298-304.

National Telecommunications and Information Administration. 2013. Exploring the digital nation: America's emerging online experience. Retrieved from https://www. ntia.doc.gov/files/ntia/publications/exploring_the_digital_nation_-_americas_ emerging_online_experience.pdf.

Organization for Economic Co-operation and Development. 2012. Households with access to a home computer. Retrieved from http://www.oecd.org/internet/ ieconomy/Final_6.a_PC\%20Households_2012.xls.

Organization for Economic Co-operation and Development. 2016. Broadband subscriptions per 100 inhabitants of OECD countries. Retrieved from http://www. oecd.org/sti/broadband/1.2-OECD-WiredWirelessBB-2015-12.xls.

Paasi, Anssi. 1998. Boundaries as social processes: Territoriality in the world of flows. Geopolitics 3 (1): 69-88.

Paasi, Anssi. 2012. Border studies reanimated: Going beyond the territorial/relational divide. Environment and Planning A 44 (10): 2303-9. 
Plantin, Lars, Kristian Daneback, Malmö University, and Faculty of Health and Society. 2009. Parenthood, information and support on the internet. A literature review of research on parents and professionals online. BMC Family Practice 10 (1): 34-.

Presson, Angela P., PhD, Ginger Partyka BS, Kristin M. Jensen MD, Owen J. Devine PhD, Rasmussen, Sonja A., MD, MS, Linda L. McCabe PhD, and McCabe, Edward R.B., MD, PhD. 2013. Current estimate of down syndrome population prevalence in the united states. Journal of Pediatrics, the 163 (4): 1163-8.

Samek, Toni. 2007. Librarianship and Human Rights : A Twenty-First Century Guide. Oxford: Chandos.

Savolainen, Reijo. 2006. Information use as gap-bridging: The viewpoint of sense-making methodology. Journal of the American Society for Information Science and Technology 57 (8): 1116-25.

Savolainen, Reijo. 2007. Information source horizons and source preferences of environmental activists: A social phenomenological approach. Journal of the American Society for Information Science and Technology 58 (12): 1709-19.

Savolainen, Reijo. 2009. Small world and information grounds as contexts of information seeking and sharing. Library and Information Science Research 31 (1): 38-45.

Sonnenwald, D. H. 1999. Evolving perspectives of human information behavior: Contexts, situations, social networks and information horizons. In T. D. Wilson, \& D. K. Allen (Eds.), Exploring the contexts of information behaviour. Proceedings of the Second International Conference on Research in Information Needs, Seeking and Use in Different Contexts, 13/15 August 1998, Sheffield, UK (pp. 176-190). Taylor Graham: New York, NY. Retrieved from http://eprints.rclis.org/7971/1/isic98\%2Bpaper.pdf.

Sonnenwald, D. H., B. S. Wildemuth, and G. L. Harmon. 2001. "A Research Method to Investigate Information Seeking Using the Concept of Information Horizons: An Example from a Study of Lower Socio-Economic Students' Information Seeking Behavior." Journal article (Paginated). The New Review of Information Behavior Research. 2001. http://eprints.rclis.org/7969/.

Talja, Sanna, Heidi Keso, and Tarja Pietiläinen. 1999. The production of 'context' in information seeking research: A metatheoretical view. Information Processing and Management 35 (6): 751-63.

Trentelman, Carla Koons. 2009. Place attachment and community attachment: A primer grounded in the lived experience of a community sociologist. Society and Natural Resources22 (3): 191-210.

Tuan, Yi-Fu. 1975. Place: An experiential perspective. Geographical Review 65 (2): 151-65.

Tuan, Yi-fu. 2001. Space and Place: The Perspective of Experience. Minneapolis: University of Minnesota Press.

Tuan, Yi-Fu. 2014. Space and place 2013. Geograficidade 4 (1): 4-13.

Veinot, Tiffany C., and Kate Williams. 2012. Following the "community" thread from sociology to information behavior and informatics: Uncovering theoretical continuities and 
research opportunities. Journal of the American Society for Information Science and Technology 63 (5): 847-64.

Wellman, B. 2002. Little boxes, glocalization, and networked individualism. Digital Cities li: Computational and Sociological Approaches 2362: 10-25.

Williams, Noelle S., Ann P. Bishop, Bertram C. Bruce, and Sharon Irish. 2012. Community informatics for whom? Journal of Education for Library and Information Science 53 (3): 218-21.

Withers, Charles W. J. 2009. Place and the "spatial turn" in geography and in history. Journal of the History of ldeas 70 (4): 637-58.

Amelia N. Gibson is an assistant professor at the School of Information and Library Science, University of North Carolina at Chapel Hill. She holds an undergraduate degree from Dartmouth College, and an MLIS and PhD from Florida State University. Her primary research interests include communities, place, and information practices, with a focus on disability and health information and environmental health. Her work has been published in First Monday and Global Qualitative Nursing Research.

Samantha Kaplan is a PhD student at the School of Information and Library Science, University of North Carolina at Chapel Hill. She holds an undergraduate degree from the University of Georgia, and an MLIS from the University of South Carolina. Her research interests include examination of misinformation and disinformation. 